\title{
Research Paper: Clomiphene Citrate to Inducte Ovulation in Females With Unexplained Infertility: A Randomized, Controlled, Clinical Trial
}

\author{
Nashwa El-Said ${ }^{1}$, Mona Abdel-Gawad ${ }^{1}$, Amr Nadim¹, Nayrouz Gozaf ${ }^{2}$, Ahmed Elsayed Hassan Elbohoty ${ }^{\text {* }}$
}

1. Department of Obstetrics and Gynecology, Faculty of Medicine, Ain Shams University, Cairo, Egypt.

2. Department of Obstetrics and Gynecology, El-Galaa Teaching Hospital, Cairo, Egypt.

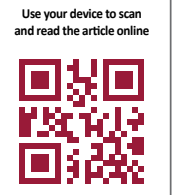

Cftation: El-Said N, Abdel-Gawad M, Nadim A, Gozaf N, Elsayed Hassan Elbohoty A. Clomiphene Citrate to Inducte Ovulation in Females With Unexplained Infertility: A Randomized, Controlled, Clinical Trial. Journal of Advanced Medical Sciences and Applied Technologies. 2017; 3(3):139-146. https://doi.org/10.32598/jamsat.3.3.139

Article info:

Received: 14 Mar. 2017

Accepted: 23 Jun. 2017

Keywords:

Clomiphene citrate,

Unexplained infertility, Clinical

pregnancy rate

\section{A B STRACT}

Objectives: The current study aimed at comparing the efficacy of Clomiphene Citrate (CC) for the expectant management of unexplained infertility in females over 3 successive cycles.

Materials \& Methods: The present randomized, controlled, clinical trial was carried out at Ain Shams University Maternity Hospital. Females with unexplained infertility for at least 12 months of unprotected regular marital life were enrolled. Eligible females were randomly assigned into one of the 2 following groups: group 1 received $100 \mathrm{mg} \mathrm{CC}$ once a day for 5 days, and group 2 was expectantly followed up without induction of ovulation. The primary outcome was the clinical pregnancy rate.

Results: A total of 113 females were enrolled in the current trial. The mean age of the subjects was $25.3 \pm 3.1$ years; ranged 20 to 33 . The clinical pregnancy rate was slightly, but significantly, higher in CC group compared with the controls; both per case ( $7 / 57$ vs. $4 / 56,12.3 \%$ vs. $7.1 \%$, respectively; $\mathrm{P}=0.357$; Relative Risk $(\mathrm{RR})=1.72 ; 95 \%$ Confidence Interval $(\mathrm{CI})=0.53$, 5.55; Number Needed to Treat $(N N T)=19)$ and per cycle $(7 / 163$ vs. $4 / 160,4.3 \%$ vs. $2.5 \%$, respectively; $\mathrm{P}=0.374 ; \mathrm{RR}=1.72 ; 95 \% \mathrm{CI}=0.51,5.75 ; \mathrm{NNT}=56$ ).

Conclusion: $\mathrm{CC}$ seems to be not effective in improving clinical pregnancy outcome compared with observation alone in females with unexplained infertility.

\section{Introduction}

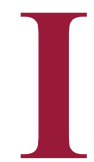

$\mathrm{n}$ spite of the advances in infertility issue, inability to conceive remains unexplained in up to $30 \%$ of well-investigated infertile couples [1]. There is no agreement on the exact definition of unexplained infertility. A diagnosis of unexplained infertility is one of exclusions. There is no consensus on the factors that should be excluded in order to assign the infertility unexplained [2]. Most of clinicians believe that the basic infertility workup should also include semen analysis, according to the World

* Corresponding Author:

Ahmed Elsayed Hassan Elbohoty, PhD

Address: Department of Obstetrics and Gynecology, Faculty of Medicine, Ain Shams University, Cairo, Egypt.

Tel: 0020 (2) 22590767

E-mail: elbohoty79@yahoo.com 
Health Organization (WHO) criteria [3], assessment of ovulation (using midluteal assessment of serum progesterone), and evaluation of tubal patency and uterine cavity (by the standard hysterosalpingogram or laparoscopy/hysteroscopy) [1, 2, 4-7].

Some clinicians add the diagnostic laparoscopy and postcoital test to that 'basic' infertility workup, although there is no consensus yet [4-6]. In addition to this diagnostic dilemma, there are much more controversial therapeutic strategies. The reasons underlying this controversy include a lack of consistency in the literature to define unexplained infertility, lack of a specific pathophysiological rationale that allows for a certain intervention in order to correct a biological defect, the relative high probability of spontaneous conception in such couples with observation alone, which reduces the confidence of any intervention effectiveness, and lastly the paucity of prospective randomized, controlled trials that evaluate the pregnancy rates in treated and untreated couples [8].

Over the past decades, there was a remarkable increase in the use of 3 main strategies: first, superovulation, in order to develop several dominant follicles that, at least theoretically, increases the chance of fertilization and pregnancy; second, Intrauterine Insemination (IUI), which should overcome cervical factors and subtle male factors; and third, In Vitro Fertilization (IVF) as a final therapeutic modality [9]. The superovulation is even controversial. There is no agreement whether to induce ovulation using oral agents (Clomiphene Citrate (CC) or aromatase inhibitors) or gonadotropins. Numerous studies were carried out regarding the efficacy of ovulation induction agents on females with unexplained infertility.

A quite recent systematic review and meta-analysis published in 2010 assessed the efficacy of CC in females with unexplained infertility. Although the authors reported no evidence for the effectiveness of $\mathrm{CC}$ on pregnancy outcome in the studied females, there was a marked heterogeneity between the studies ranged from $34 \%$ to $58 \%$ [10]. The current study aimed at comparing the efficacy of $\mathrm{CC}$ for the expectant management of unexplained infertility in females over 3 successive cycles.

\section{Materials and Methods}

The present randomized, controlled, clinical trial was performed at Ain Shams University Maternity Hospital from September 2011 to August 2012. The study protocol was in accordance with the Declaration of Helsinki for Ethical Medical Research (last revision, Korea, 2008) and was approved by the Ethical Committee of Obstet- rics and Gynecology Department, Ain Shams University, Cairo, Egypt. All subjects signed the informed written consent following the explanation of study goals and procedures. All participants were free to withdraw from the study at any time or decline without being adversely impacted regarding the medical services.

The study included females attending the outpatient infertility clinic for unexplained infertility for at least 12 months of unprotected regular marital life. Unexplained infertility is defined when there were a normal husband's semen analysis, documented ovulation, and normal and patent uterine cavity and tubes [8]. A normal husband's semen analysis was defined according the WHO 2010 criteria: volume $\geq 2 \mathrm{~mL}$, count $\geq 15 \times 10^{6}$ per $\mathrm{mL}$, normal morphology $<4 \%$, and progressive motility $\geq 32 \%$ [3]. Ovulation was documented with a midluteal serum progesterone $\geq 3 \mathrm{ng} / \mathrm{mL}$. Uterine cavity and tubes were assessed using either hysterosalpingogram or combined hysteroscopy/laparoscopy with chromopertubation. Females $>35$ years old who previously received $\mathrm{CC}$ for more than 6 months, as well as the ones who reported serious CC-related side effects; e.g. blurring of vision were excluded from the study.

\section{Randomization, allocation, and intervention}

Eligible females were randomly assigned to one of the 2 groups: group 1 received $100 \mathrm{mg} \mathrm{CC} \mathrm{(Clomid} \AA$, Aventis, Egypt) per os, once a day, starting from the cycle day 2 to the cycle day 6 ; and group 2 was expectantly followed up without induction of ovulation. The computer-generated randomization method was used to assign subjects to the groups. The allocated groups were concealed in seriallynumbered sealed opaque envelops that was opened just after the recruitment. Females in both groups received the allocated treatment 30 minutes before the procedure, and were instructed not to take any analgesics.

Transvaginal ultrasound scan, for measuring the endometrial thickness and the number and average dimension of the follicle(s), was started on the cycle day 9, and repeated every 48 hours till reaching the size of a mature dominant follicle ( $\geq 18 \mathrm{~mm}$ ). The diameter of the follicle was taken as the average of 2 perpendicular dimensions. When mature follicle size was obtained ( $\geq 18 \mathrm{~mm}$ ), intramuscular human Chorionic Gonadotropin (hCG) (Choriomon ${ }^{\circledR}$, IBSA, Switzerland) was administered at a single dose of 10,000 IU. Sexual intercourse was timed on the day of triggering ovulation, and then, daily for the next 3 to 4 days.

Transvaginal ultrasound scan was repeated 48 hours after triggering ovulation to document successful ovu- 
lation (by the appearance of the characteristic corpus luteum and presence of free fluid in the pouch of Douglas). Serum pregnancy test was performed 16 days after triggering the ovulation. Clinical pregnancy was confirmation 2-3 weeks after a positive serum pregnancy test by positive embryonic pulsations on transvaginal ultrasound scan. Transvaginal scan was performed using the 4-7 MHz transvaginal probe Medison X4 Ultrasound Set (Samsung/Medison $\AA$, Seoul, South Korea). Females who failed to get pregnant were subjected to the same study course for further 2 successive cycles.

\section{Study outcomes}

The primary outcome was the clinical pregnancy rate, defined as sonographic detection of a viable intrauterine gestational sac. Viability was defined as the presence of detectable embryonic pulsations. Secondary outcomes included the number of mature follicles, endometrial thickening in ovulation, multiple pregnancy rate, as well as medication-related side effects.

\section{Sample size justification}

Sample size calculation was performed using EpiInfo ${ }^{\circledR}$ version 6.0 , setting the type- 1 error $(\alpha)$ at 0.05 and the power $(1-\beta)$ at $80 \%$. Data from the literature 10 showed that the spontaneous pregnancy rate in couples with unexplained infertility was 0.23 per cycle. A Cochrane systematic review [10] showed that CC can significantly increase the pregnancy rate in couples with unexplained infertility almost 2.5 folds $(\mathrm{OR}=2.5,95 \%$ Confidence Interval $(\mathrm{CI})=1.35,4.62)$. According to the values, a minimal sample size was calculated as 38 cases in each group. Assuming a dropout rate of $20 \%$, at least 47 cases were required in each group.

\section{Statistical methods}

Data were statistically analyzed with SPSS ${ }^{\circledR}$ for Windows version 20. To analyze differences between the groups, the independent student $t$ test (for parametric numerical variables), the Mann-Whitney U-test (for nonparametric numerical variables), chi-squared test, risk ratio, and 95\% CI (for the categorical variables) were employed. The Yates continuity correction was applied to the chi-square test whenever one or more of observed values were less than 5 . $\mathrm{P}<0.05$ were considered as the level of significance.

\section{Results}

A total of 113 females were enrolled in the current trial. Figure 1 shows a diagram of the study course. The mean age of the subjects was $25.3 \pm 3.1$ years; ranged 20 to 33 . The mean Body Mass Index (BMI) was $23.8 \pm 2.6 \mathrm{~kg} / \mathrm{m}^{2}$; ranged 19.3 to 32.4 . The mean duration of infertility was $1.7 \pm 0.5$ years; ranged 1 to 4 . There were no significant differences between the groups regarding the basic characteristics (Table 1).

The clinical pregnancy rate was slightly, but significantly, higher in females of the CC group compared with the controls; both per case (7/57 vs. 4/56, $12.3 \%$ vs. $7.1 \%$, respectively; $\mathrm{P}=0.357$; Relative Risk $(R R)=1.72 ; 95 \% \quad C I=0.53,5.55$; Number Needed to Treat $(\mathrm{NNT})=19)$ and per cycle $(7 / 163$ vs. $4 / 160$, $4.3 \%$ vs. $2.5 \%$, respectively, $\mathrm{P}=0.374 ; \mathrm{RR}=1.72 ; 95 \%$ $\mathrm{CI}=0.51,5.75 ; \mathrm{NNT}=56)($ Table 2$)$.

The mean endometrial thickness was higher in control group compared with the $\mathrm{CC}$ group. The median number of mature follicles was significantly higher in the CC group. The rates of multiple pregnancy and early miscarriage were low in the study subjects (Table 3 ).

The overall rate of side effects was higher in the $\mathrm{CC}$ group, but the difference between the groups was insignificant ( $8.8 \%$ vs. $1.8 \%$; $\mathrm{P}=0.216)$. Side effects included headache, blurring of vision, vaginal dryness, and ovarian cyst formation (Table 3 ).

Table 1. Baseline characteristics in both groups

\begin{tabular}{cccc}
\hline & Group 1 (CC Group) & Group 2 (Control Group) & P \\
\hline Age (year) & $25.2 \pm 2.9$ & $25.4 \pm 3.1$ & 0.740 \\
\hline BMI (kg/m²) & $23.9 \pm 2.7$ & $23.7 \pm 2.9$ & 0.722 \\
\hline Duration of infertility (year) & $1.7 \pm 0.51$ & $1.8 \pm 0.49$ & 0.320 \\
\hline
\end{tabular}

BMI: Body Mass Index

JAMSAT

Data are expressed as mean \pm SD.

Analysis was perfumed using the independent student's $t$ test. 
Table 2. Clinical pregnancy rate in both groups

\begin{tabular}{cccccc}
\hline $\begin{array}{c}\text { Clinical Pregnancy } \\
\text { Rate }\end{array}$ & $\begin{array}{c}\text { Group 1 } \\
\text { (CC Group) }\end{array}$ & $\begin{array}{c}\text { Group 2 } \\
\text { (Control Group) }\end{array}$ & P & $\begin{array}{c}\text { RR } \\
\text { (95\% Cl) }\end{array}$ & NNT \\
\hline Per case & $7 / 57(12.3 \%)$ & $4 / 56(7.1 \%)$ & 0.357 & $1.72(0.53$ to 5.55) & 19 \\
Per cycle & $7 / 163(4.3 \%)$ & $4 / 160(2.5 \%)$ & 0.374 & $1.72(0.51$ to 5.75) & 56 \\
\hline Data are shown as number (percentage). & & & & & \\
JAMSAT
\end{tabular}

Analysis was performed using chi-square test.

RR: Risk Ratio; CI: Confidence Interval

NNT: Number Needed to Treat

\section{Discussion}

The rationale for inducing ovulation in 'ovulatory' females with unexplained infertility came from 2 points: it may overcome subtle defect in ovulation not uncovered by conventional tests, and it may enhance the likelihood of pregnancy by increasing the number of available oocytes, and thus, raising the chance for successful fertilization [10]. However, such theoretical reasoning seems impractical. Most of the studies indicated no benefit from adding $\mathrm{CC}$, as a treatment, for unexplained infertility; some studies showed small benefit from combining it to IUI [11-14].

\section{Conclusion}

The current study showed a slight added benefit from prescribing $\mathrm{CC}$ for the induction of ovulation over the expectant (i.e. observation alone) management of unexplained infertility in ovulatory females; this added benefit was neither statistically nor clinically significant. From the statistical point of view, the relatively wide $95 \% \mathrm{CI}$ of the risk ratio of clinical pregnancy rate both per case $(\mathrm{RR}=1.72 ; 95 \% \mathrm{CI}=0.53,5.55)$ and per cycle $(\mathrm{RR}=1.72 ; 95 \% \mathrm{CI}=0.51,5.75)$ highlights the unpowered results regarding the clinical pregnancy rate as an

Table 3. Secondary Outcomes in Both Groups

\begin{tabular}{|c|c|c|c|c|c|c|}
\hline & & $\begin{array}{l}\text { Group } 1 \\
\text { (CC Group) }\end{array}$ & $\begin{array}{c}\text { Group } 2 \\
\text { (Control Group) }\end{array}$ & $\mathbf{P}$ & $\begin{array}{c}\text { RR } \\
(95 \% \mathrm{Cl})\end{array}$ & NNH \\
\hline & $\begin{array}{l}\text { Endometrial thickness } \\
\qquad(\mathrm{mm})\end{array}$ & $9.4 \pm 1.3$ & $10.5 \pm 1.8$ & $<0.001^{1}$ & - & - \\
\hline & No. of mature follicles & $2(1-2)$ & $1(1-1)$ & $0.003^{2}$ & - & - \\
\hline & Multiple pregnancy & $1(1.8 \%)$ & $0(0 \%)$ & $0.993^{3}$ & $\mathrm{NE}$ & 57 \\
\hline & Early miscarriage & $1(1.8 \%)$ & $1(1.8 \%)$ & $0.483^{3}$ & $0.98(0.06$ to 15.33$)$ & 3192 \\
\hline \multirow{6}{*}{ Side effects } & Overall & $5(8.8 \%)$ & $1(1.8 \%)$ & $0.216^{3}$ & $4.91(0.59$ to 40.73$)$ & 14 \\
\hline & Headache & $1(1.8 \%)$ & $1(1.8 \%)$ & $0.483^{3}$ & $0.98(0.06$ to 15.33$)$ & 3192 \\
\hline & Blurring of vision & $1(1.8 \%)$ & $0(0 \%)$ & $0.993^{3}$ & NE & 57 \\
\hline & Pelvic pain & $0(0 \%)$ & $0(0 \%)$ & $\mathrm{NE}^{3}$ & NE & NE \\
\hline & Vaginal dryness & $2(3.5 \%)$ & $0(0 \%)$ & $0.483^{3}$ & NE & 29 \\
\hline & Cyst formation & $2(3.5 \%)$ & $0(0 \%)$ & $0.483^{3}$ & $N E$ & 29 \\
\hline
\end{tabular}

Data are shown as mean $\pm \mathrm{SD}$, median (IQR), or number (percentage).

JAMSAT

1. Analysis was performed using the independent student $t$ test.

2. Analysis was performed using the Mann-Whitney U-test.

3. Analysis was performed using chi-squared test.

RR: Risk Ratio; CI: Confidence Interval; NNH: Number Needed to Harm; NE: Not Estimable due to nullity in one or both groups 


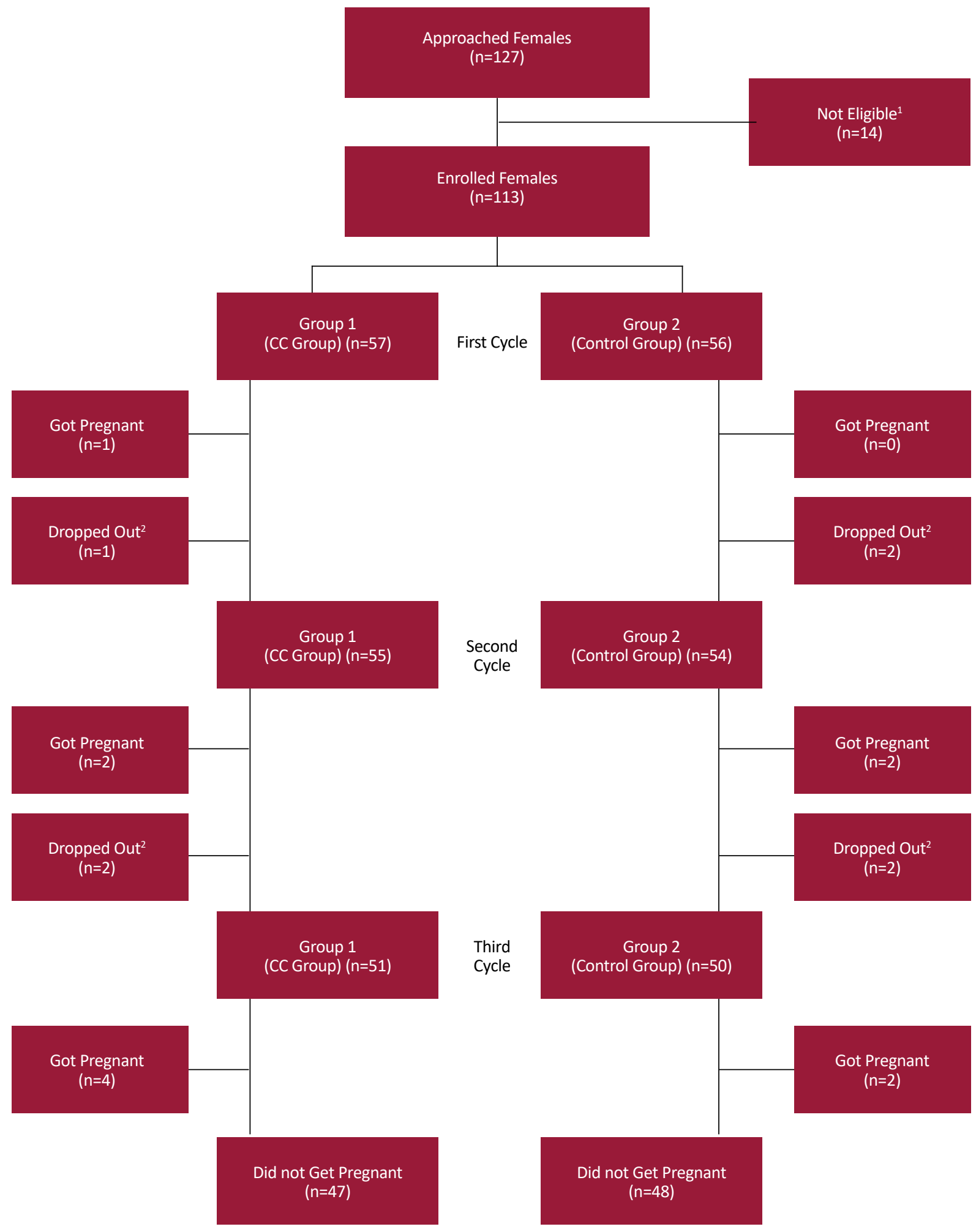

Figure 1. Flow diagram of the study course

1. Not eligible female: the one who did not meet the inclusion criteria.

2. Dropped-out cases due to loss of contact or serious side effect (e.g. blurring of vision) 
outcome. Meanwhile, from the clinical point of view, the NNTs for the added benefit regarding the clinical pregnancy rate of 19 (for the rate per case) and 56 (for the rate per cycle) reflects a very marginal clinical benefit. Yet, considering the relative low cost and low-risk of serious side effects or adverse sequelae of CC (particularly the multiple pregnancy and Ovarian Hyper-Stimulation Syndrome (OHSS), the suggested treatment may be offered to some females with unexplained infertility, but after consulting with physician.

A similar conclusion was made by Hughes et al., in a systematic review and meta-analysis on 7 randomized, controlled trials including 1159 females. The authors found no significant difference in the clinical pregnancy rate between the $\mathrm{CC}$ (with or without IUI) and placebo groups (odd ratios for $\mathrm{CC}$ without $\mathrm{IUI}=1.66$; $95 \% \mathrm{CI}=0.58,4.8 ; \mathrm{P}=0.35) 11$. The authors, however, recommended that females should be counseled about the 3 -fold increased risk of ovarian cancer using $\mathrm{CC}$ for more than 12 cycles; an observation that was previously reported by Rossing [15] and Whittemore [16].

On the contrary to the results of the current large systematic review, an earlier well-designed, double-blind, randomized trial showed that the pregnancy rate was significantly improved following the consumption of $\mathrm{CC}$, compared with the placebo group. The difference between the groups may be attributed to the lack of pregnancy in the placebo group during the 4 cycles of observation. Nevertheless, 7 pregnancies were reported in this group during a 6-month follow-up period [17].

In conclusion, $\mathrm{CC}$ seems to be ineffective on the improvement of clinical pregnancy outcome compared with observation alone in females with unexplained infertility. Nevertheless, owing to the heterogeneity in the large published systematic review and meta-analysis, and the quite conflicting results of some well-designed trials, larger trials are needed to confirm or negate the current study conclusion.

\section{Acknowledgments}

This research did not receive any specific grant from funding agencies in the public, commercial, or not-forprofit sectors.

\section{Conflict of Interest}

The authors declared no conflicts of interest.

\section{References}

[1] The Practice Committee of the American Society for Reproductive Medicine. Effectiveness and treatment for unexplained infertility. Fertility and Sterility. 2006; 86:111-4. doi: 10.1016/j.fertnstert.2006.07.1475

[2] Definitions of infertility and recurrent pregnancy loss. Fertility and Sterility. 2008; 90(5):S60. doi: 10.1016/j.fertnstert.2008.08.065

[3] Cooper TG, Noonan E, von Eckardstein S, Auger J, Baker HWG, Behre HM, et al. World Health Organization reference values for human semen characteristics. Human Reproduction Update. 2009; 16(3):231-45. doi: 10.1093/humupd/ dmp048

[4] Collins JA, Crosignani PG. Unexplained infertility: a review of diagnosis, prognosis, treatment efficacy and management. International Journal of Gynecology \& Obstetrics. 1992; 39(4):267-75. doi: 10.1016/0020-7292(92)90257-j

[5] Templeton AA, Penney GC. The incidence, characteristics, and prognosis of patients whose infertility is unexplained. Fertility and Sterility. 1982; 37(2):175-82. doi: 10.1016/s00150282(16)46035-8

[6] Hamada A, Esteves SC, Nizza M, Agarwal A. Unexplained Male infertility: diagnosis and Management. International Brazilian Journal Of Urology. 2012; 38(5):576-94. doi: 10.1590/ s1677-55382012000500002

[7] Hatasaka H. New Perspectives for Unexplained Infertility. Clinical Obstetrics and Gynecology. 2011; 54(4):727-33. doi: 10.1097/grf.0b013e3182353e54

[8] Jose-Miller AB, Boyden JW, Frey KA. Infertility. American Family Physician. 2007; 75(6):849-56. PMID: 17390595

[9] Kamath MS, Bhattacharya S. Demographics of infertility and management of unexplained infertility. Best Practice \& Research Clinical Obstetrics \& Gynaecology. 2012; 26(6):729-38. doi: 10.1016/j.bpobgyn.2012.08.001

[10] Hughes E, Brown J, Collins JJ, Vanderkerchove P. Clomiphene citrate for unexplained subfertility in women. Hughes E, editor. Cochrane Database of Systematic Reviews. 2010; (1):CD000057. doi: 10.1002/14651858.cd000057.pub2

[11] Crosignani PG, Walters DE, Soliani A. The ESHRE multicentre trial on the treatment of unexplained infertility: a preliminary report. 1991; 6(7):953-8. doi: 10.1093/oxfordjournals. humrep.a137468

[12] Guzick DS, Carson SA, Coutifaris C, Overstreet JW, Factor-Litvak $\mathrm{P}$, et al. Efficacy of superovulation and intrauterine insemination in the treatment of infertility. National Cooperative Reproductive Medicine Network. New England Journal of Medicine. 1999; 340(3):177-83. doi: 10.1056/NEJM199901213400302

[13] Goverde AJ, McDonnell J, Vermeiden JP, Schats R, Rutten FF, Schoemaker J. Intrauterine insemination or in-vitro fertilisation in idiopathic subfertility and male subfertility: a randomised trial and cost-effectiveness analysis. Lancet. 2000; 355(9197):13-8. doi: 10.1016/s0140-6736(99)04002-7

[14] Aboulghar MA, Mansour RT, Serour GI, Al-Inany HG. Diagnosis and management of unexplained infertility: an update. Archives of Gynecology and Obstetrics. 2003; 267(4):17788. doi: $10.1007 /$ s00404-002-0300-0 
[15] Rossing MA, Daling JR, Weiss NS, Moore DE, Self SG. Ovarian tumors in a cohort of infertile women. New England Journal of Medicine. 1994; 331(12):771-6. doi: 10.1056/ nejm199409223311204

[16] Harris R, Whittemore AS, Itnyre J. Characteristics relating to ovarian cancer risk: collaborative analysis of 12 us casecontrol studies. American Journal of Epidemiology. 1992; 136(10):1204-11. doi: 10.1093/oxfordjournals.aje.a116428

[17] Glazener CMA, Coulson C, Lambert PA, Watt EM, Hinton RA, Kelly NG, et al. Clomiphene treatment for women with unexplained infertility: placebo-controlled study of hormonal responses and conception rates. Gynecological Endocrinology. 1990; 4(2):75-83. doi: 10.3109/09513599009012324 
